RH: Ring-tailed lemur thoracic radiology

\title{
Radiographic thoracic anatomy of the ring-tailed lemur (Lemur catta)
}

M. Makungu ${ }^{1,2}$, W.M. du Plessis ${ }^{3}$, M. Barrows ${ }^{4}$, H.B. Groenewald ${ }^{1}$ \& K.N. Koeppel ${ }^{5}$

1 Department of Anatomy and Physiology, Faculty of Veterinary Science, University of Pretoria, Onderstepoort, South Africa

2 Department of Veterinary Surgery and Theriogenology, Faculty of Veterinary Medicine, Sokoine University of Agriculture, Morogoro, Tanzania

3 Ross University School of Veterinary Medicine, Basseterre, St. Kitts, West Indies

$4 \quad$ Bristol Zoo Gardens, Clifton, Bristol, UK

5 Johannesburg Zoo, Parkview, Johannesburg, South Africa

\section{Keywords}

Lemuridae - morphology - primate - radiography - thorax

\section{Correspondence}

Dr. Modesta Makungu, Department of Anatomy and Physiology, Faculty of Veterinary Science, University of Pretoria, Private Bag X04, Onderstepoort 0110, South Africa.

Tel: +27 125298246 ;

Fax: +27 125298320 ;

e-mail: modesta_makungu@yahoo.com

9 figures and 3 tables 


\section{Abstract}

Background The ring-tailed lemur (Lemur catta) is a quadruped arboreal primate primarily distributed in south and south-western Madagascar. This study was carried out to describe the normal radiographic thoracic anatomy of the ring-tailed lemur as a reference for clinical use.

Methods Radiography of the thorax was performed in 15 captive ring-tailed lemurs during their annual health examinations.

Results Normal radiographic reference ranges for thoracic structures were established and ratios were calculated, such as the vertebral heart score (VHS). The mean VHS on the right lateral and dorsoventral views was $8.92 \pm 0.47$ and $9.42 \pm 0.52$, respectively. Conclusions Differences exist in the normal radiographic thoracic anatomy of primates. Knowledge of the normal radiographic thoracic anatomy of individual species is important and fundamental to assist in clinical cases and for accurate diagnosis of diseases.

\section{Introduction}

The ring-tailed lemur (Lemur catta) is classified as a near-threatened species by the International Union for Conservation and Nature [10]. It belongs to the suborder Strepsirrhini [20]. Strepsirrhines are characterised by retaining primitive characteristics such as bicornuate uterus, pointed muzzle, rhinarium, small brain case, tapetum lucidum, epitheliochorial placenta, prominent scent glands and open eye sockets $[2,12]$.

In Lemurs, the trachea has complete cartilaginous rings, and the principle bronchi are relatively short with the right being shorter than the left [22]. The lungs are conical in 
shape with the apex being more pointed than that of the human lungs [22]. The apex does not protrude past the thoracic inlet into the root of the neck. It only reaches to the level of the caudal border of the first costal arch [22]. The left lung is divided into two lobes, that is, cranial and caudal lobes. The cranial lobe is larger than the caudal lobe. The former is incompletely subdivided by a short fissure into cranial and caudal parts [22]. The right lung consists of four lobes: cranial, middle, caudal and accessory lobes [22] (Fig. 1).

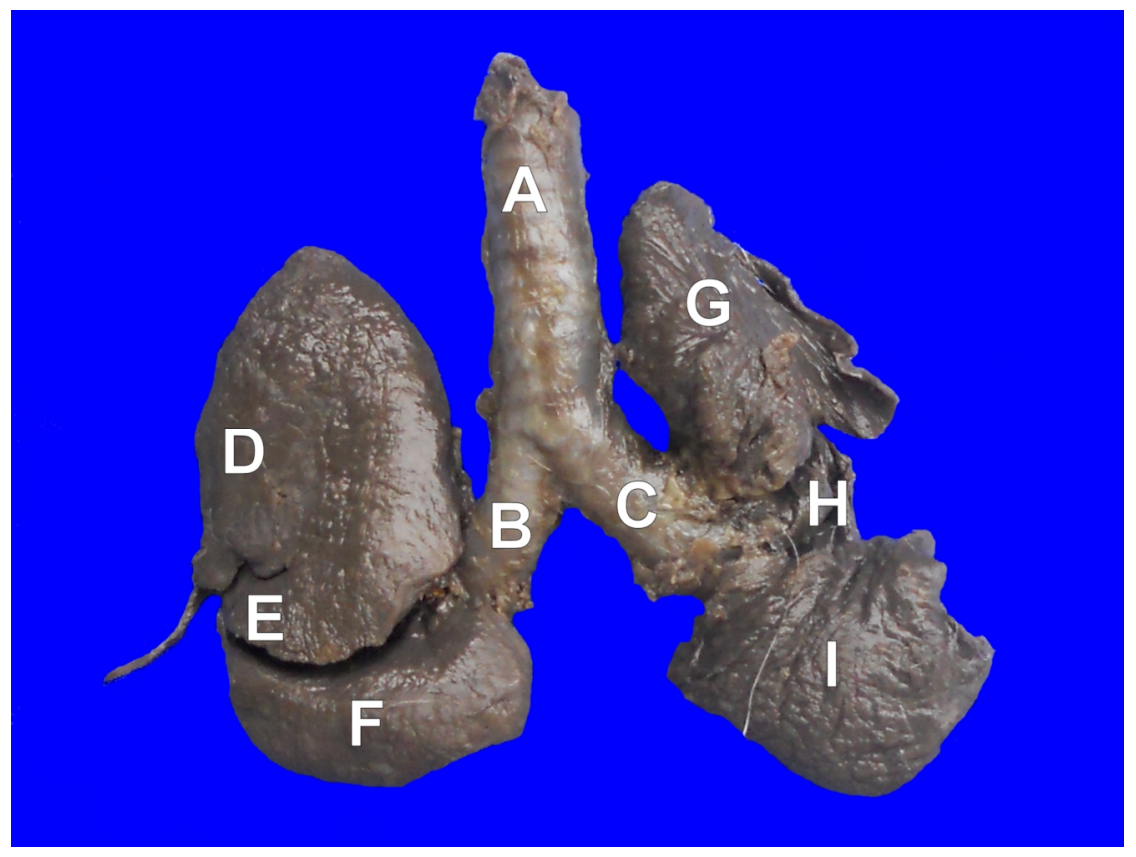

Fig. 1 Dorsal photographic view of formalin-fixed lungs of a 5-year-old female ring-tailed lemur. Note the complete cartilaginous rings of the trachea. $A=$ trachea, $B=$ left brochus, $C=$ right brochus, $D=$ cranial part of the cranial lobe of the left lung, $E=$ caudal part of the cranial lobe of the left lung, $F=$ caudal lobe of the left lung, $\mathrm{G}=$ cranial lobe of the right lung, $\mathrm{H}=$ middle lobe of the right lung and $\mathrm{I}=$ caudal lobe of the right lung.

Radiography is commonly used in primates, and several authors have documented the normal radiographic anatomy of the thorax in primates, which provides 
a reference for diagnosis of disease $[1,3,25,26,28,31,33]$. Various thoracic diseases have been reported in ring-tailed lemurs such as pneumonia [7,30], tuberculosis [27], hydatidosis [14], neoplasia [23], pleural effusions [12], lung atelectasis [21], encephalomyocarditis virus infection [5] and sudden acute respiratory distress syndrome (M. Barrows, personal communication).

This study was performed to describe the normal radiographic thoracic anatomy of the ring-tailed lemur as a species-specific reference. To the best of the authors' knowledge, this has not been published previously.

\section{Materials and Methods}

\section{Animals}

A total of 15 captive ring-tailed lemurs from the Bristol zoo (6), United Kingdom (UK), Johannesburg zoo (8) and Montecasino Bird Gardens (1), South Africa (SA) were radiographed during their annual health examinations. Animals were considered healthy based on history, physical and clinical examinations, haematological evaluation, faecal examination and kidney and liver function tests. The age of the animals ranged from 1.40 to 25.70 years (mean: $10.34 \pm 7.63$ years). The minimum and maximum weights of the animals were 2.10 and $3.44 \mathrm{~kg}$, respectively (mean: $2.92 \pm 0.42 \mathrm{~kg}$ ). Of the 15 animals, 10 were females and five were males. There was no significant difference in the mean age $(p=0.39)$ and weight $(p=0.08)$ of the animals between males and females. This study was approved by the Bristol Zoo Gardens Research Committee and Animal Use and Care Committee (AUCC) of the University of Pretoria. 


\section{Radiography}

Radiography of the thorax was performed under general anaesthesia. Animals were fasted for 8-12 hours, but water was given ad libitum until shortly before general anaesthesia. Anaesthesia was induced by either isoflurane (IsoFlo: Abbott Laboratories Ltd., Berkshire, UK) via a mask or intramuscular injection of medetomidine hydrochloride (Domitor: Pfizer Laboratories Ltd., Sandton, SA) and ketamine hydrochloride (Kyron Laboratories Ltd., Benrose, SA) combination. All animals were maintained by isoflurane anaesthesia (IsoFlo; Abbott Laboratories Ltd.: Isofor; Safe Line Pharmaceuticals Ltd., Roodepoort, South Africa) under intubation.

Right lateral $(R L)$ and dorsoventral (DV) radiographic views of the thorax were taken at the end of inspiration using a table-top technique. The forelimbs were positioned cranially for the RL view. For the DV view, the forelimbs were pulled cranially in 4 of 15 animals, whereas in 11 of 15 animals, the elbows were positioned to either side of the thorax. Radiographs were made using either a Roentgen 703 (GEC Medical Equipment Ltd., Middlesex, UK) or EVA-HF525 (Comed Medical System Co. Ltd., Kyunggi, Korea). In the former, a source to image distance (SID) of $105 \mathrm{~cm}$ was used with $60 \mathrm{kVp}$ and $3 \mathrm{mAs}(100 \mathrm{~mA}$ and $0.03 \mathrm{~s})$. Images were obtained using a computed radiography (CR) unit Regius Model 110 (Konica Minolta Medical and Graphic INC., Tokyo, Japan). With the EVA-HF525, a SID of $95 \mathrm{~cm}$ was used. Medium speed screentype films (Fujifilm Corporation, Tokyo, Japan) were used in combination with RAREX green regular intensifying screens (Okamoto manufacturing Co. Ltd., Tokyo, Japan). An exposure of $46 \mathrm{kVp}$ and $1.25 \mathrm{mAs}(25 \mathrm{~mA}$ and $0.05 \mathrm{~s})$ was used with an automatic $\mathrm{x}$-ray film processor model CP-345 (ELK Corporation, Tokyo, Japan). 


\section{Evaluation}

The height (Fig. 2) of the thoracic vertebrae and sternebrae was measured on the RL view along a line that extended between the cranioventral and craniodorsal borders of the vertebral bodies and sternebrae [18]. The length (Fig. 2) of the thoracic vertebrae and sternebrae was measured on the RL view from the midpoint of the cranial end plate to the midpoint of the caudal end plate [18]. The depth of the thorax (TDp) (Fig. 2) was

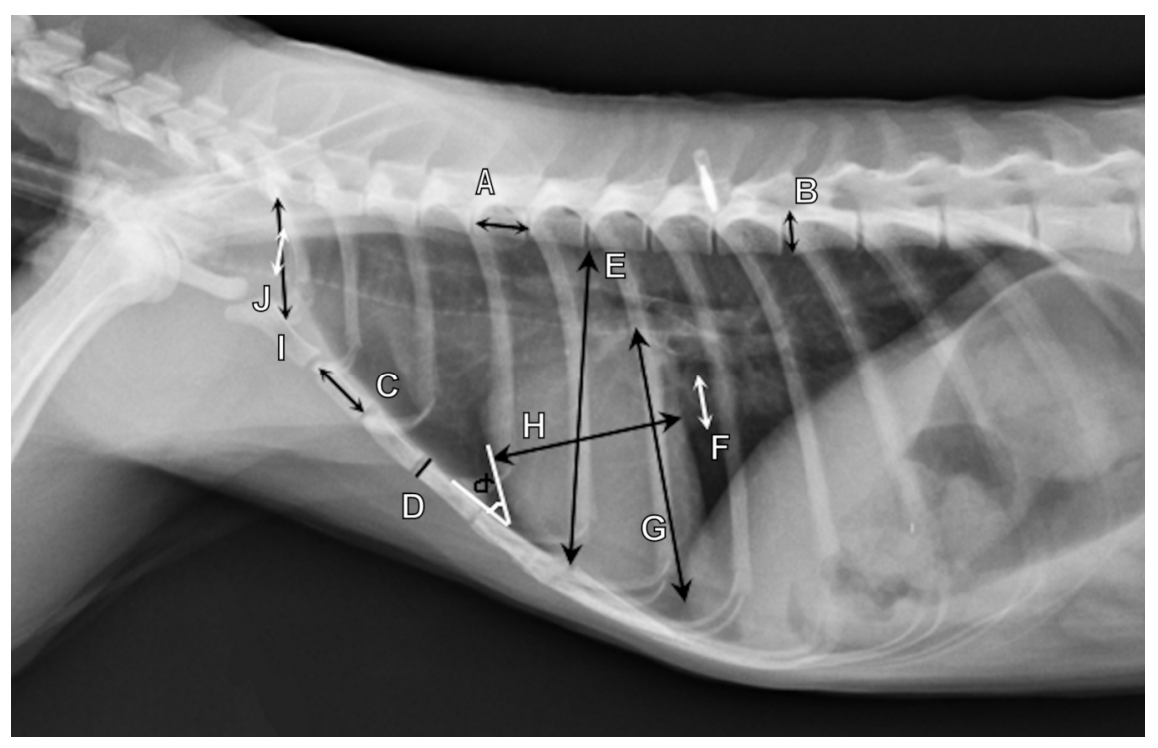

Fig. 2 Right lateral thoracic radiograph of a 2.8-year-old female ring-tailed lemur illustrating selected radiographic measurements. $A=$ vertebral body length, $B=$ vertebral body height,$C=$ length of sternebra, $\mathrm{D}=$ height of sternebra, $\mathrm{E}=$ thoracic depth, $\mathrm{F}=$ caudal vena cava diameter, $\mathrm{G}=$ cardiac silhouette longaxis measurement, $\mathrm{H}=$ cardiac silhouette short axis measurement, $\mathrm{I}=$ thoracic inlet diameter, $\mathrm{J}=$ trachea diameter and $\alpha=$ angle of cardiac inclination.

measured on the RL view from the dorsocaudal border of the last sternebra (sternebra four or five) to the closest edge of the vertebral column [16]. The width of the thorax (TW) (Fig. 3) was measured on the DV view as the maximum distance between the left and right pleural surfaces of the seventh ribs. 


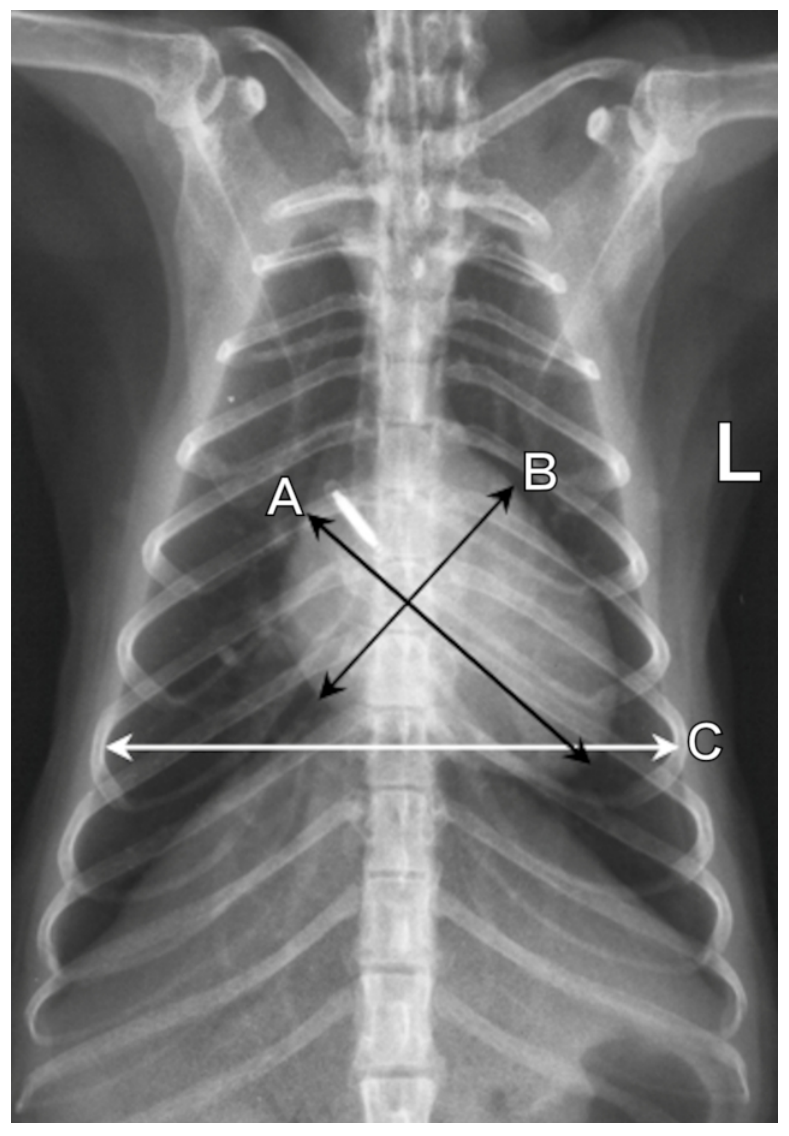

Fig. 3 Dorsoventral thoracic radiograph of a 3-year-old male ring-tailed lemur illustrating selected radiographic measurements. $A=$ cardiac silhouette long-axis measurement, $B=$ cardiac silhouette short axis measurement and $C=$ width of the thorax. $L$, left.

The visibility, shape and location of thoracic organs were recorded. The vertebral heart score (VHS) was measured on the DV and RL views (Figs 2 and 3 ) as previously described in dogs [4]. The angle of cardiac inclination ( $\mathrm{ACl})$ was measured as the angle formed between the right cardiac border and the sternum (Fig. 2) on the RL view [1]. The maximum diameter of the caudal vena cava (CVC) and aorta was measured on the $\mathrm{RL}$ view caudal to the cardiac silhouette and cranial to the diaphragm. The diameter of the CVC was also compared to that of the aorta and the length of the thoracic vertebral body (VL) above the tracheal bifurcation [15]. 
The ratio of the tracheal diameter (TD) to thoracic inlet diameter (TID) was calculated on the RL view [9]. The TID was measured from the ventral aspect of the vertebral column at the midpoint of the most cranial rib to the dorsal surface of the manubrium at its point of minimal thickness (Fig. 2). The TD (Fig. 2) was measured between the internal surfaces of the tracheal wall perpendicular to the tracheal long axis at the point where the thoracic inlet distance crosses the midpoint of the tracheal lumen [9]. The location of the carina with respect to thoracic vertebra was determined on the

$\mathrm{RL}$ and $\mathrm{DV}$ views. In cases where the carina was not visible on the $\mathrm{RL}$ view, the crossing point of the mainstem bronchi was used to locate its position. The angle between the mainstem bronchi (MSB) was measured on the DV view as the angle of divergence between the caudal borders of the left and right mainstem bronchi [8]. The crossing point of the diaphragmatic crura/crus to the thoracic or lumbar vertebra on the $\mathrm{RL}$ view was recorded in relationship to cranial thoracic vertebrae during inspiration.

\section{Data analysis}

Data were analysed using Stat View ${ }^{\circledR}$ statistical package (SAS Institute, Cary, NC, USA). Mean, range and standard deviation were calculated. Student's $t$-test was used to compare the mean age and weight between male and female animals as well as means of VHS on RL view vs. DV view. Statistical significance was accepted at $P \leq 0.05$. Data are expressed as mean \pm SD. 
Table 1 Radiographic measurements $(\mathrm{cm})$ of thoracic $(T)$ vertebrae in captive ring-tailed lemurs not compensated for magnification

\begin{tabular}{|c|c|c|c|c|}
\hline Vertebra & Variables & Number & Mean \pm SD & $\begin{array}{l}\text { Range } \\
\text { (Min-Max) }\end{array}$ \\
\hline \multirow[t]{2}{*}{ T1 } & Length & 14 & $0.68 \pm 0.06$ & $0.52-0.80$ \\
\hline & Height & 14 & $0.28 \pm 0.03$ & $0.25-0.30$ \\
\hline \multirow[t]{2}{*}{ T2 } & Length & 14 & $0.74 \pm 0.05$ & $0.68-0.80$ \\
\hline & Height & 14 & $0.31 \pm 0.04$ & $0.25-0.40$ \\
\hline \multirow[t]{2}{*}{ T3 } & Length & 14 & $0.77 \pm 0.04$ & $0.70-0.85$ \\
\hline & Height & 14 & $0.33 \pm 0.02$ & $0.30-0.35$ \\
\hline \multirow[t]{2}{*}{ T4 } & Length & 14 & $0.80 \pm 0.04$ & $0.75-0.85$ \\
\hline & Height & 14 & $0.36 \pm 0.03$ & $0.30-0.40$ \\
\hline \multirow[t]{2}{*}{ T5 } & Length & 14 & $0.80 \pm 0.03$ & $0.75-0.85$ \\
\hline & Height & 14 & $0.37 \pm 0.04$ & $0.30-0.40$ \\
\hline \multirow[t]{2}{*}{ T6 } & Length & 14 & $0.83 \pm 0.03$ & $0.78-0.86$ \\
\hline & Height & 14 & $0.40 \pm 0.02$ & $0.35-0.45$ \\
\hline \multirow[t]{2}{*}{ T7 } & Length & 14 & $0.86 \pm 0.05$ & $0.79-0.90$ \\
\hline & Height & 14 & $0.44 \pm 0.04$ & $0.39-0.50$ \\
\hline \multirow[t]{2}{*}{ T8 } & Length & 14 & $0.91 \pm 0.05$ & $0.83-0.96$ \\
\hline & Height & 14 & $0.48 \pm 0.05$ & $0.40-0.55$ \\
\hline \multirow[t]{2}{*}{ T9 } & Length & 14 & $0.97 \pm 0.04$ & $0.90-1.03$ \\
\hline & Height & 14 & $0.53 \pm 0.04$ & $0.49-0.60$ \\
\hline \multirow[t]{2}{*}{ T10 } & Length & 14 & $1.06 \pm 0.05$ & $1.00-1.17$ \\
\hline & Height & 14 & $0.58 \pm 0.05$ & $0.50-0.65$ \\
\hline \multirow[t]{2}{*}{ T11 } & Length & 14 & $1.16 \pm 0.04$ & $1.10-1.24$ \\
\hline & Height & 14 & $0.61 \pm 0.04$ & $0.50-0.66$ \\
\hline \multirow[t]{2}{*}{ T12 } & Length & 14 & $1.26 \pm 0.05$ & $1.20-1.34$ \\
\hline & Height & 14 & $0.66 \pm 0.04$ & $0.59-0.70$ \\
\hline \multirow[t]{2}{*}{ T13 } & Length & 1 & $1.35 \pm 0.00$ & $1.35-1.35$ \\
\hline & Height & 1 & $0.70 \pm 0.00$ & $0.70-0.70$ \\
\hline
\end{tabular}




\section{Results}

Patient positioning was better with forelimbs adjacent to the thorax compared with cranially on the DV view. Radiographic measurements and findings are summarised in Tables 1-3.

Table 2 Radiographic measurements $(\mathrm{cm})$ of the manubrium sterni (MS), sternebrae (S) and xiphoid process $(\mathrm{XP})$ not compensated for magnification in captive ring-tailed lemurs

\begin{tabular}{|c|c|c|c|c|}
\hline & Variables & Number & Mean \pm SD & $\begin{array}{l}\text { Range } \\
\text { (Min-Max) }\end{array}$ \\
\hline \multirow[t]{2}{*}{ MS } & Length & 15 & $1.37 \pm 0.14$ & $1.16-1.61$ \\
\hline & Height & 15 & $0.71 \pm 0.10$ & $0.50-0.90$ \\
\hline \multirow[t]{2}{*}{ S1 } & Length & 15 & $1.03 \pm 0.10$ & $0.90-1.20$ \\
\hline & Height & 15 & $0.43 \pm 0.06$ & $0.30-0.50$ \\
\hline \multirow[t]{2}{*}{ S2 } & Length & 15 & $1.07 \pm 0.07$ & $0.99-1.20$ \\
\hline & Height & 15 & $0.42 \pm 0.07$ & $0.30-0.50$ \\
\hline \multirow[t]{2}{*}{ S3 } & Length & 11 & $1.07 \pm 0.10$ & $0.95-1.30$ \\
\hline & Height & 11 & $0.39 \pm 0.07$ & $0.30-0.50$ \\
\hline \multirow[t]{2}{*}{ S4 } & Length & 7 & $1.21 \pm 0.24$ & $0.95-1.60$ \\
\hline & Height & 7 & $0.37 \pm 0.04$ & $0.30-0.40$ \\
\hline \multirow[t]{2}{*}{ S5 } & Length & 3 & $1.18 \pm 0.14$ & $1.10-1.35$ \\
\hline & Height & 3 & $0.35 \pm 0.05$ & $0.30-0.40$ \\
\hline \multirow[t]{2}{*}{ XP } & Length & 15 & $1.86 \pm 0.28$ & $1.50-2.71$ \\
\hline & Height & 15 & $0.21 \pm 0.07$ & $0.12-0.32$ \\
\hline
\end{tabular}


Table 3 Radiographic findings and measurements of the thorax not compensated for magnification in captive ring-tailed lemurs

\begin{tabular}{|c|c|c|c|}
\hline Variables & Number & Mean \pm SD & $\begin{array}{l}\text { Range } \\
\text { (Min - Max) }\end{array}$ \\
\hline TDp [cm] & 15 & $5.43 \pm 0.46$ & $4.72-6.20$ \\
\hline TW [cm] & 15 & $7.28 \pm 0.49$ & $6.41-8.20$ \\
\hline TDp: TW & 15 & $0.75 \pm 0.07$ & $0.63-0.86$ \\
\hline Sternebrae & 15 & $4.60 \pm 0.51$ & $4.00-5.00$ \\
\hline Anticlinal vertebra & 15 & $10.20 \pm 0.41$ & $10.00-11.00$ \\
\hline $\mathrm{ACl}\left[{ }^{\circ}\right]$ & 15 & $34.13 \pm 3.77$ & $30.00-45.00$ \\
\hline VHS [RL] & 15 & $8.92 \pm 0.47$ & $8.00-9.60$ \\
\hline VHS [DV] & 13 & $9.42 \pm 0.52$ & $8.60-10.20$ \\
\hline CVC diameter [cm] & 9 & $0.70 \pm 0.13$ & $0.60-1.97$ \\
\hline CVC: Aorta & 4 & $0.88 \pm 0.06$ & $0.81-0.95$ \\
\hline CVC: VL & 8 & $0.85 \pm 0.22$ & $0.63-1.21$ \\
\hline Aorta diameter [cm] & 4 & $0.73 \pm 0.06$ & $0.67-0.80$ \\
\hline \multicolumn{4}{|l|}{ Carina } \\
\hline Vertebra [RL] & 15 & $6.73 \pm 0.70$ & $6.00-8.00$ \\
\hline Vertebra [DV] & 14 & $6.50 \pm 0.65$ & $6.00-8.00$ \\
\hline Angle between MSB & 14 & $82.60 \pm 8.26$ & $70.00-95.00$ \\
\hline \multicolumn{4}{|l|}{$\left[{ }^{0}\right]$} \\
\hline $\mathrm{TD}[\mathrm{cm}]$ & 14 & $0.71 \pm 0.04$ & $0.65-0.79$ \\
\hline TID [cm] & 14 & $1.99 \pm 0.07$ & $1.80-2.09$ \\
\hline TD: TID & 14 & $0.36 \pm 0.02$ & $0.33-0.40$ \\
\hline \multicolumn{4}{|l|}{ Cranial crus } \\
\hline Inspiration & 15 & $12.49 \pm 0.86$ & $11.00-13.60$ \\
\hline
\end{tabular}




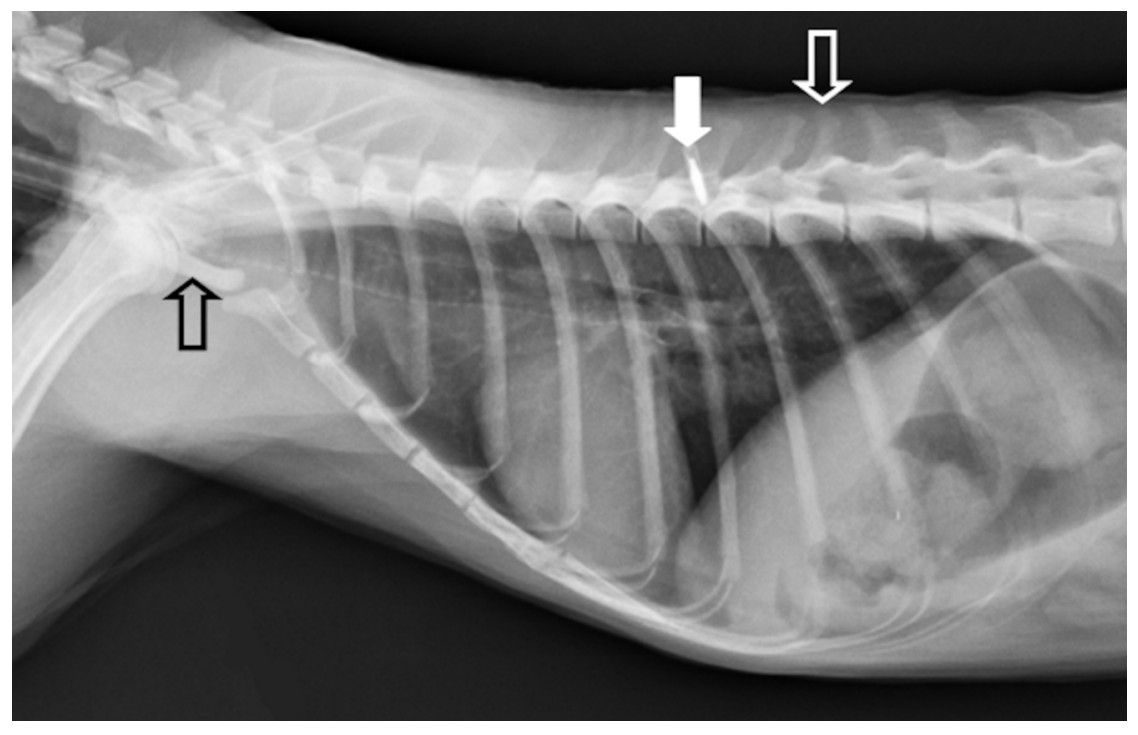

Fig. 4 Right lateral thoracic radiograph of a 2.8-year-old $(2.44 \mathrm{~kg})$ female ring-tailed lemur. Note the increase in length and height of the thoracic vertebral bodies from cranial to caudal, well-developed clavicles (open black arrow) and a very narrow thoracic inlet. The trachea with mineralized cartilage rings is aligned almost parallel to the thoracic spine. Note also the almost parallel alignment of the heart with the ribs. The upright positioned cardiac silhouette is wider than two intercostal spaces, but does not exceed three intercostal spaces. Note the anticlinal thoracic vertebra number 10 (open white arrow) and lack of visibility of the carina. The metal opacity (white arrow) represents the microchip.

\section{Musculoskeletal system}

Of 15 animals, 14 had 12 thoracic vertebrae (Fig. 4) whereas one animal (female) had 13 thoracic vertebrae. The anticlinal vertebra was thoracic vertebra 10 (T10) in 12 of 15 animals (Fig. 4) and T11 in 3 of 15 . The thoracic spine was fairly horizontally aligned (Figs 4 and 5). The height and length of thoracic vertebral bodies increased from cranial to caudal (Fig. 4). The spinous processes were almost of the same height (Fig. 4). Spondylosis deformans of thoracic vertebrae was seen in two animals aged 19 and 22 years. Of the 15 animals, 14 had 12 pairs of ribs of which the last pair was floating (not connected to the costal arch) (Fig. 4). The animal with 13 thoracic vertebrae had 13 


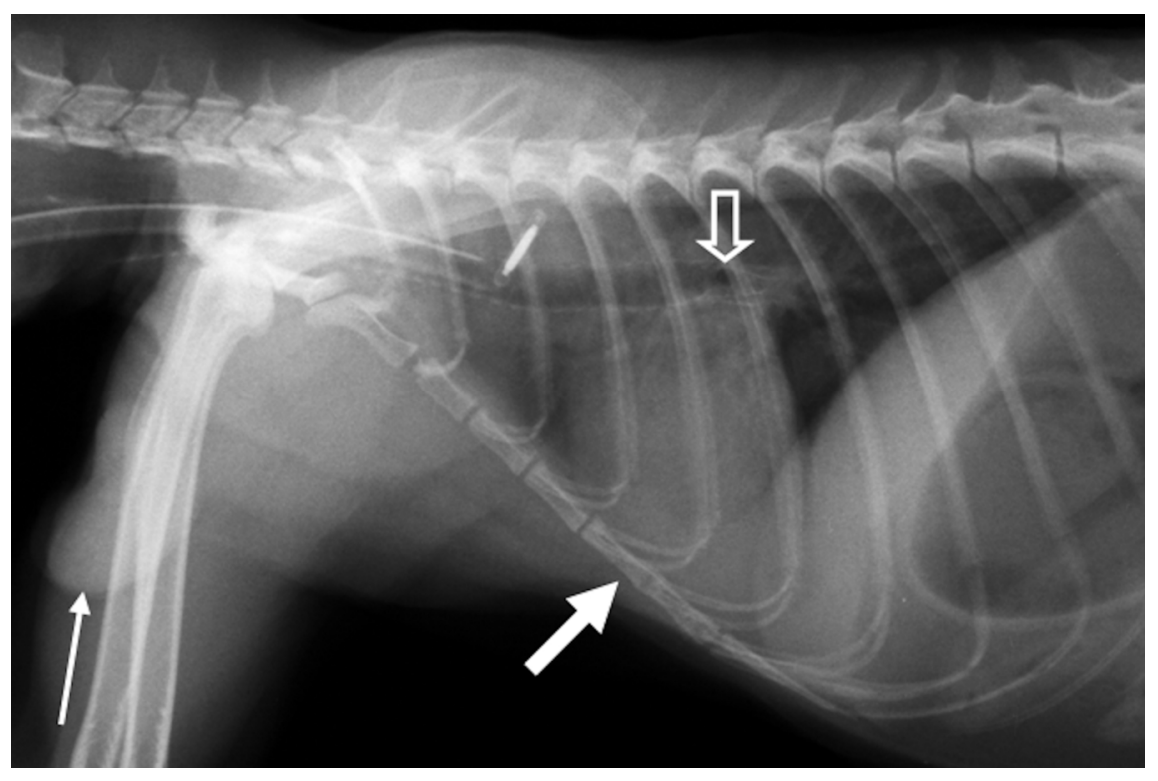

Fig. 5 Right lateral thoracic radiograph of a 7.3-year-old $(3.02 \mathrm{~kg})$ male ring-tailed lemur. Note the fusion of the last two sternebrae (thick white arrow) and extensive cardiodiaphragmatic contact. Note also an almost parallel alignment of the trachea with the thoracic spine, clearly visible carina (open white arrow) and the presence of scent glands (thin white arrow).

pairs of ribs of which the last two pairs were floating. The sternum was fairly straight and slender. It consisted of a manubrium sterni, four (6/15) or five (9/15) (Fig. 5) sternebrae and a xiphoid process. The cranial extremity of the manubrium sterni was wider than the caudal extremity. The last two (Fig. 5) or three sternebrae were fused in six and two animals, respectively. The thoracic inlet was very narrow (Figs 4 and 5), and the clavicles were well developed (Figs 4 and 6).

\section{Cardiovascular system}

In all animals, the cardiac silhouette was in contact with the diaphragm (Fig. 4). The cardiodiaphragmatic contact increased in heavier (Figs 5 and 7) compared with lighter (Figs 4 and 6) animals. On the RL view, the ovoid heart was aligned almost parallel to 


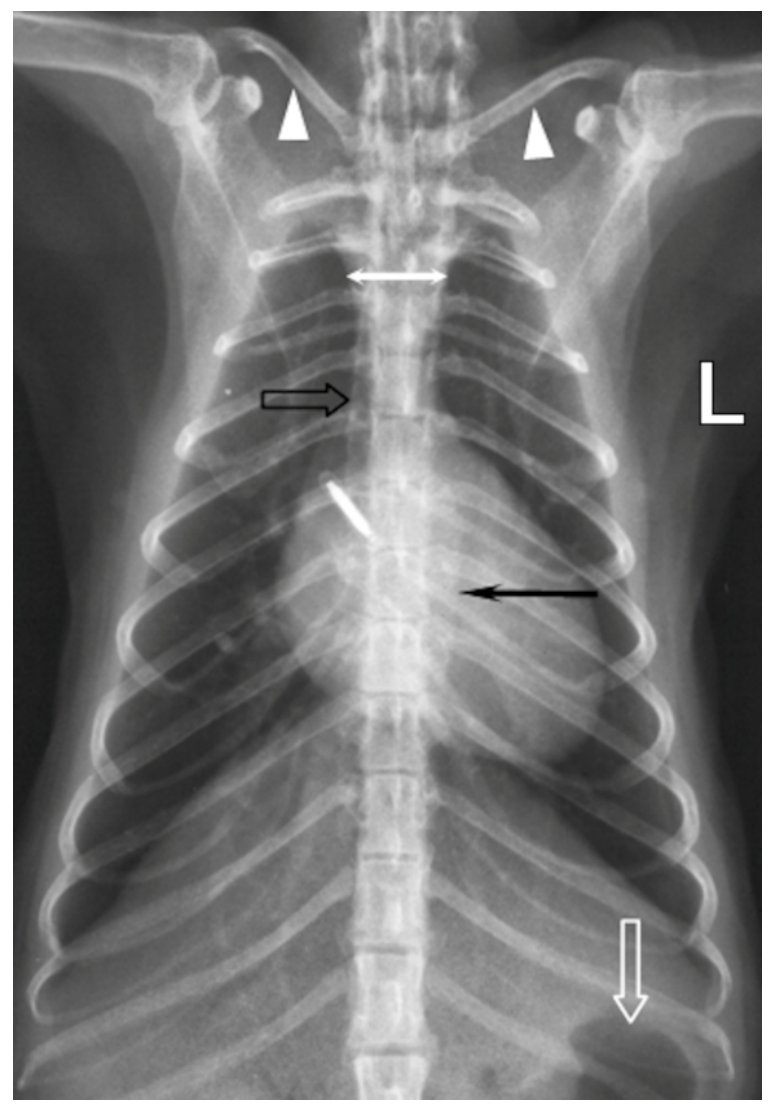

Fig. 6 Dorsoventral thoracic radiograph of a 3-year-old $(2.31 \mathrm{~kg})$ male ring-tailed lemur. Note the extensive cardiodiaphragmatic contact and more diagonal positioned cardiac silhouette. Note also the visualization of the left margin of the aorta (black arrow). Note the position of the trachea slightly to the right of the spine (open black arrow) and an almost similar thickness of the craniodorsal mediastinum and thoracic spine (white arrow). Note also the concentration of the gastric gas in the gastric fundus (open white arrow) and well-developed clavicles (white arrow heads). L, left.

the ribs and was upright positioned (Figs 4 and 5). The cranial border of the cardiac silhouette was poorly seen (Fig. 5) except in lighter animals (Fig. 4). The caudal vena cava (CVC) was clearly seen in nine animals (Fig. 4) and was not clearly visible in six animals. The visibility of the CVC was better in light (Fig. 4) vs. heavy animals (Fig. 5). In the majority of the animals (11/15), the aorta was not clearly seen or not seen at all (Figs 4 and 5). The size of the cardiac silhouette was wider than two intercostal spaces, but 


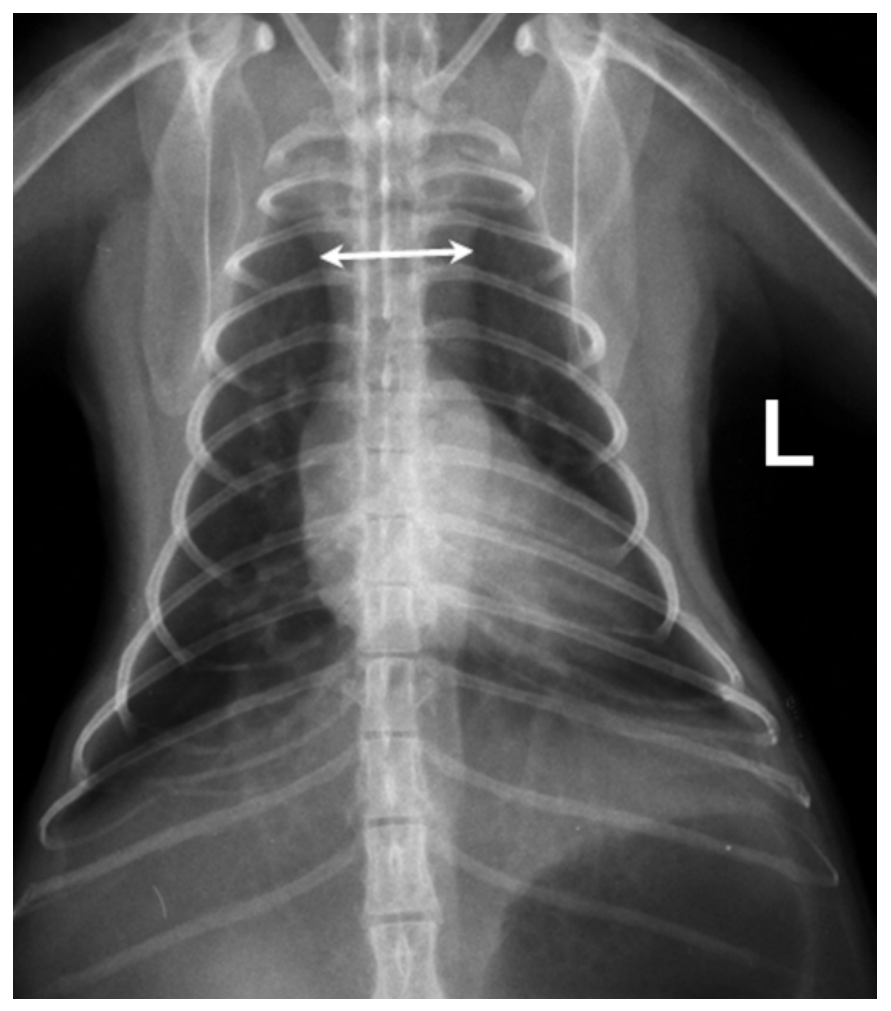

Fig. 7 Dorsoventral thoracic radiograph of a 12.3-year-old $(3.24 \mathrm{~kg})$ female ring-tailed lemur. Note the more extensive cardiodiaphragmatic contact when compared to Fig. 5. Note also the more prominent craniodorsal mediastinum (white arrow) when compared to Fig. 5 and the poorly visible trachea superimposed on the spine and sternum. L, left.

did not exceed three intercostal spaces (Figs 4 and 5) on the RL view. On the DV view, the ovoid cardiac silhouette was more diagonal in position (Figs 6 and 7). The apex was positioned to the left, and there was extensive cardiodiaphragmatic contact (Figs 6 and 7), which increased in heavy animals (Fig. 7) compared to lighter animals (Fig. 6). The caudal lobar pulmonary veins and arteries were not clearly visible. There was a significant difference $(p=0.003)$ in the mean VHS obtained on the RL and DV views. Pericardial fat was seen in three heavier animals ( $3.3 \mathrm{~kg}$ and above). On the $\mathrm{RL}$ view, pericardial fat was seen along the cranial border of the heart (Fig. 8). On the DV view, it was seen around the cardiac apex (Fig. 9) and at 8-11 o'clock. 


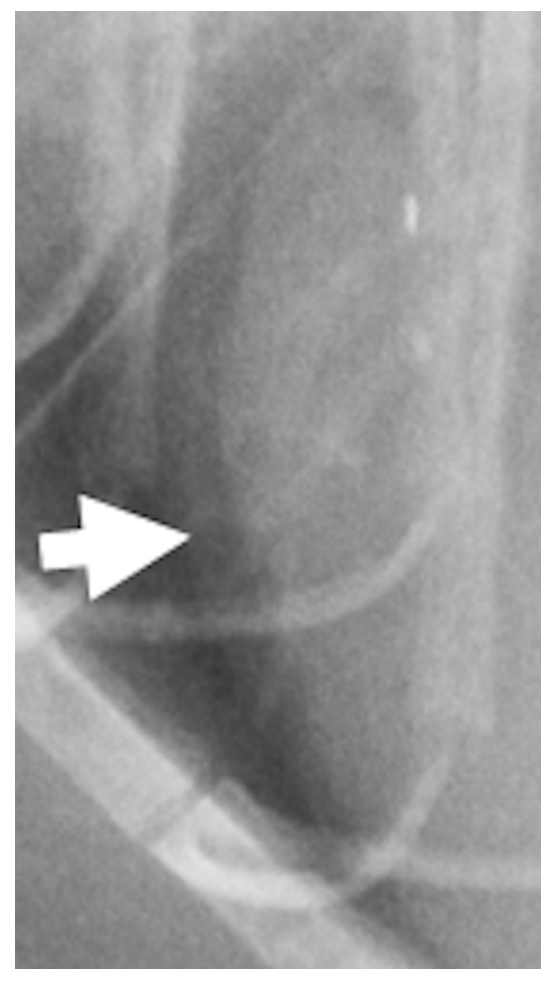

Fig. 8 Close-up of RL thoracic radiograph of the cardiac silhouette of a 4.8-year-old $(3.3 \mathrm{~kg})$ male ringtailed lemur. Note the presence of fat opacity along the cranial border of the heart (white arrow).

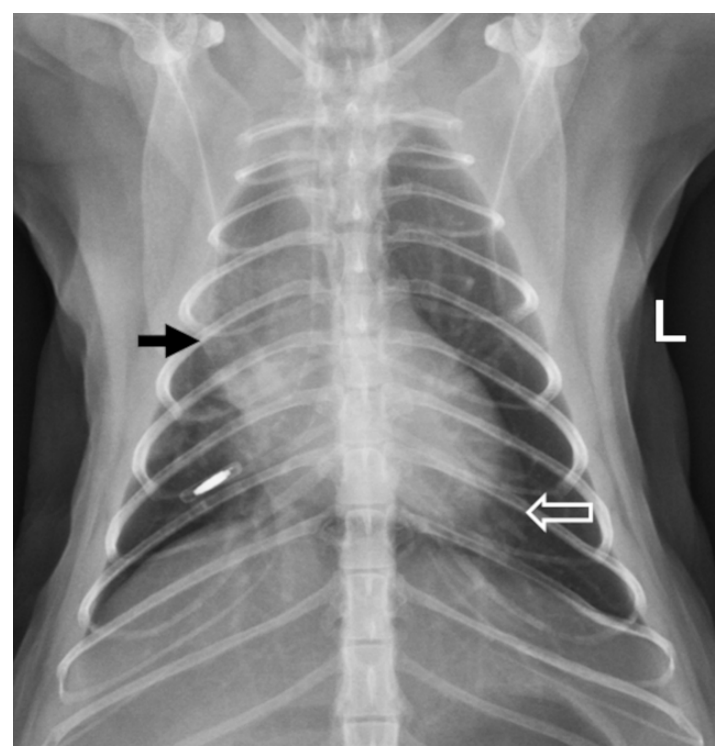

Fig. 9 Dorsoventral thoracic radiograph of a 4.8-year-old $(3.3 \mathrm{~kg})$ male ring-tailed lemur. Note the presence of fat opacity (open white arrow) around the apex of the heart and alveolar lung pattern (black arrow) in the right hemithorax resulting in border effacement of the right aspect of the cardiac silhouette. L, left. 


\section{Respiratory system}

On the RL view, the trachea with its mineralised cartilage rings was seen in all animals (Fig. 4). It was parallel (8/15) (Figs 4 and 5) or deviated dorsally to the spine (6/15). In only one animal, did it diverge from the spine. The carina was frequently (12/15) not clearly visible or not visible at all (Fig. 4) on the RL view. It was clearly visible in only three animals (Fig. 5). On the DV view, the carina was clearly visible in 14 of 15 animals. There was no significant difference $(P=0.16)$ in the mean position of the carina with respect to thoracic vertebra on the DV and RL views. On the DV view, in 12 of 13 animals, the trachea was running slightly to the right of the spine (Fig. 6). In one animal, it was superimposed on the spine (Fig. 7). In 7 of 15 animals, interstitial, bronchointerstitial and alveolar patterns were observed in the right hemithorax with severe changes seen adjacent to the right margin of the cardiac silhouette which was partially being obscured (Fig. 9). The caudoventral mediastinal reflection was seen in 3 of 15 animals. The craniodorsal mediastinum exceeded the width of the superimposed spine and appeared prominent in heavy animals (Fig. 7).

\section{Other findings}

The thoracic lymph nodes were not identified in any view. A pair of mammary glands was seen in female animals as increased soft tissue opacity ventral to the thorax partly superimposed over the triceps brachii muscle on the RL view. Area of increased soft tissue opacity in the proximal half of the humerus was seen in male animals representing the brachial scent glands (Fig. 5). 


\section{Discussion}

The mean weight of the animals observed in this study $(2.92 \mathrm{Kg})$ was higher than the reported mean weight of the ring-tailed lemurs in the wild $(2.2 \mathrm{~kg})[6,12]$ and previously reported (male: $2.705 \mathrm{~kg}$; female: $2.678 \mathrm{~kg}$ ) in captivity [13]. In captivity, lemurs are commonly observed to be overweight or even obese mainly as a result of change in their lifestyle [6].

In primates, variations in the number of thoracic vertebrae occur within a species $[1,31]$. The number of thoracic vertebrae observed in this species $(12-13)$ is similar to the common marmoset (Callithrix jacchus) [31]. However, the mean number of thoracic vertebrae (12.1) is different from the reported study in the common marmoset (12.59) [31] and indicates that there is very little variation in the number of thoracic vertebrae in this species when compared to the common marmoset. The increase in size of the thoracic vertebral bodies from cranial to caudal observed in this species has also been reported in the vervet monkey (Chlorocebus sabaeus) [33] and in other primate species [2]. Variation in the number and fusion of sternebrae has also been reported in the common marmoset [31]. Further, the mean number of sternebrae observed in this study (4.6) is similar to the reported study in the common marmoset (4.5) [31]. The spondylosis deformans observed in this study was characterised by osteophytes formation at the vertebral body end plates similar to dogs, although cranial thoracic vertebrae were also involved. In dogs the thoracolumbar and lumbosacral regions are commonly affected [32].

Measurement of thoracic width in this study was performed between the left and right pleural surfaces of the seventh ribs, rather than the eighth as in domestic cats and 
dogs $[4,17]$ due to lack of visibility of the thoracic pleura at rib 8 in some of the animals. The lack of visibility of the thoracic pleura at rib 8 in some of the animals is the result of abdominal dominance in this species. The mean VHS obtained in this study lies between the values reported in domestic cats [17] and dogs [4]. The higher value of the VHS obtained from DV view than RL view has also been observed in domestic cats [17] and dogs [4]. For VHS measurements, pericardial fat must be distinguished from the actual cardiac silhouette to avoid exaggerated VHS and misdiagnosis of cardiomegaly. Pericardial fat has also been seen in domestic cats and dogs $[11,16,24,29]$. The mean $\mathrm{ACl}$ obtained in this study $\left(34.13^{\circ}\right)$ is intermediate between the domestic cat $\left(25-30^{\circ}\right)$ and dog $\left(40^{\circ}\right)[19]$.

The poorly defined cranial border of the cardiac silhouette observed in this study on the RL view is believed to be due to the deposition of fat in the pericardial sac. In obese domestic cats, the cardiac silhouette margins may not be clearly seen due to pericardial fat [16]. Pericardial fat in domestic cats was distinguished more readily on the lateral radiographs, and the radiographic contrast between the true cardiac silhouette and fat was sometimes enhanced by decreasing $k \bigvee p$ and increasing $m A s$ [16]. The extensive cardiodiaphragmatic contact in this species is similar to the reported study in the common marmoset [31] and is due to the abdominal dominance in these species.

The parallel or dorsal deviation of the trachea to the thoracic spine which was observed in this species on the RL view is normal and should not be misinterpreted as dorsal displacement of the trachea due to cardiac enlargement, cranial mediastinal mass, pleural effusion [9] or substernal fat [16]. The parallel alignment of the trachea to the thoracic spine has also been observed in dogs with dorsoventrally compressed thorax such as the Dachshund and Welsh corgi [29]. The animal in which the trachea 
diverged from the spine had also kyphosis and spondylosis deformans of the entire thoracic spine. The position of the trachea slightly to the right of the spine which was observed in the majority of the animals on the DV view is similar to dogs $[9,29]$. The presence of mineralised tracheal cartilage rings in all animals in this study suggests that it is a normal feature in this species and not an incidental finding or ageing change. The poor visibility of the carina on the RL view in the majority of the animals in this study is similar to the common marmoset [31], but contrary to the vervet monkey [33]. The observed interstitial, brochointerstitial and alveolar patterns are believed to be due to RL recumbency during radiography causing gravity-dependent atelectasis, which would be consistent with their location in the right hemithorax. This would be also supported by the fact that heavier animals were prone to more severe atelectasis. None of the animals with lung pattern revealed respiratory disease on clinical examination. In domestic cats and dogs the right middle lung lobe collapses before the other lobes because of a high pleural surface area: lung volume ratio, leading to less collateral ventilation. The same may hold true for the ring-tailed lemur due to occurrence of severe changes adjacent to the right margin of the cardiac silhouette which was partially obscured.

The radiographic thoracic anatomy of the ring-tailed lemur more closely resembles the common marmoset [31] than other reported New and Old World monkeys $[1,28,33]$. Variations exist in the normal radiographic thoracic anatomy of primates $[1,28,31,33]$. Knowledge of the normal radiographic thoracic anatomy of individual species is important and fundamental for accurate diagnosis of diseases. 


\section{Acknowledgements}

The authors would like to thank the Organisation for Women in Science for the Developing World (OWSDW), Swedish International Development Cooperation Agency (SIDA), University of Pretoria, Johannesburg (JHB) and Bristol zoos for supporting this study. Montecasino Bird Gardens for permission to use their animal for this study. Drs Brett Gardner and Kathryn Perrin, Ms. Fania Mohlala, sisters and animal handlers of the JHB and Bristol zoos for their assistance during radiography. Mrs. Charmaine Vermeulen and Mrs. Wilma Olivier of the University of Pretoria for their assistance in photography and administrative work, respectively.

\section{References}

1 Alves FR, Costa FB, Machado PP, Diniz AN, Araújo AVC, Ambrósio CE, Guerra PC: Anatomical and radiographic appearance of the capuchin monkey thoracic cavity (Cebus apella). Pesq Vet Bra 2012; 32:1345-50.

2 Ankel-Simons F: Primate Anatomy: An Introduction. Boston: Academic Press, 2007.

3 Brining DL, Mattoon JS, Kercher L, LaCasse RA, Safronetz D, Feldmann H, Parnell MJ: Thoracic radiography as a refinement methodology for the study of H1N1 influenza in cynomologus macaques (Macaca fascicularis). Comparative Med 2010; 60:389-95.

4 Buchanan JW, Bücheler J: Vertebral scale system to measure canine heart size in radiographs. J Am Vet Med Assoc 1995; 206:194-9. 
5 Canelli E, Luppi A, Lavazza A, Lelli D, Sozzi E, Martin AMM, Gelmetti D, Pascotto E, Sandri C, Magnone W, Cordioli P: Encephalomyocarditis virus infection in an Italian zoo. Virol J 2010; 7 (64):1-7.

6 Goodchild S, Schwitzer C: The problem of Obesity in Captive lemurs. Int Zoo News 2008; 55:353-7.

7 Hamerton BCAE: Report on the deaths occurring in the Society's Gardens during the year 1943. J Zool 1944; 114:307-21.

8 Haskin PH, Goodman LR: Normal tracheal bifurcation angle: a reassessment. Am J Roentgenol 1982; 139:879-82.

9 Hayward N, Schwarz T, Weisse C: The trachea. In: BSVA Manual of Canine and Feline Thoracic Imaging. Schwarz \& Johnson (eds). Gloucester: BSAVA, 2008, 213-27.

10 IUCN. IUCN Red list of threatened species, Version1. 2013. [cited 2013 July]; Available from: http://www.iucnredlist.org.

11 Johnson V, Hansson K, Maï W, Dukes-McEwan J, Lester N, Schwarz T, Chapman P, Morandi F: The heart and major vessels. In: BSVA Manual of Canine and Feline Thoracic Imaging. Schwarz \& Johnson (eds). Gloucester: BSAVA, 2008, 86-176.

12 Jungle RE: Prosimians. In: Zoo and Wild Animal Medicine, $5^{\text {th }}$ Edition. Fowler \& Miller (eds). Missouri: Saunders, 2003, 334-46.

13 Kappeler PM: Patterns of sexual; dimorphism in body weight among prosimians primates. Folia Primatol 1991; 57:132-46.

14 Kondo H, Wada Y, Bando G, Kosuge M, Yagi K, Oku Y: Alveolar hydatidosis in a gorilla and ring-tailed lemur in Japan. J Vet Med Sci 1996; 58:447-9. 
15 Lehmkuhl LB, Bonagura JD, Biller DS, Hartman WM: Radiographic evaluation of caudal vena cava size in dogs. Vet Radiol Ultrasound 1997; 38:94-100.

16 Litster AL, Buchanan JW: Radiographic and echocardiographic measurement of the heart in obese cats. Vet Radiol Ultrasound 2000; 41:320-5.

17 Litster AL, Buchanan JW: Vertebral scale system to measure heart size in radiographs of cats. J Am Vet Med Assoc 2000; 216:210-4.

18 Nelson NC, Mattoon JS, Anderson DE: Radiographic appearance of the thorax of clinically normal alpaca crias. Am J Vet Res 2011; 72:1439-48.

19 Nickel R, Schummer A, Seiferle E, Frewein J, Wilkens H, Wille KH: The Anatomy of the Domestic Animals Vol.3. Berlin: Springer-Verlag, 1986.

20 Nowak RM: Order Primate. In: Walker's Mammals of the World. Nowak (ed.). Baltimore: The Johns Hopkins University Press, 1999, 490-631.

21 Palotay JL, Uno H: Hydatid disease in four nonhuman primates. Am Vet Med Assoc 1975; 167:615-8.

22 Patten CJ: The form and position of the thoracic and abdominal viscera of the ruffed lemur (Lemur varius). Trans Royal Acad Med Ireland 1899;17:652-77.

23 Pye GW, Bennette RA, Terrell SP, Ginn PE, McSherry LJ, Herry LJ, Alleman AR: T-cell-Rich B-cell lymphoma in a ring-tailed lemur (Lemur catta). J Zoo Wildl Med 2000; 31:388-93.

24 Rudorf $\mathrm{H}$, Taeymans $\mathrm{O}$, Johnson $\mathrm{V}$ : Basics of thoracic radiography and radiology. In: BSAVA Manual of Canine and Feline Thoracic Imaging. Schwarz \& Johnson (eds). Gloucester: BSAVA, 2008, 1-19. 
25 Schillaci MA, Jones-Engel L, Heidrich JE, Benamore R, Pereira A, Paul N: Thoracic radiography of pet macaques in Sulawesi, Indonesia. J Med Primatol $2008 ; 37: 141-5$.

26 Schillaci MA, Parish S, Jones-Engel L: Radiographic measurement of the cardiothoracic ratio in pet macaques from Sulawesi, Indonesia. Radiography 2009; 15:29-33.

27 Schmidt RE: Tuberculosis in a ring-tailed lemur (Lemur catta). J Zoo Wild Med 1975; 6:11-2.

28 Silverman S, Morgan JP: Thoracic radiography of the normal rhesus macaque (Macaca mulatta). Am J Vet Res 1980; 41:1704-19.

29 Thrall DE, Robertson ID: Atlas of Normal Radiographic Anatomy and Anatomic Variants in the Dog and Cat. St. Louis: Elsevier, 2011.

30 Tuten $\mathrm{HC}$, Miller HC, Ellis AE: Cuterebrid myiasis (Diptera: Oestridae) in captive ring-tailed lemurs (Lemur catta) at a South Carolina Zoo. J Zoo Wildl Med 2011; 42:504-7.

31 Wagner WM, Kirberger RM: Radiographic anatomy of the thorax and abdomen of the common marmoset (Callithrix jacchus). Vet Radiol Ultrasound $2005 ; 46: 217-24$.

32 Widmer WR, Thrall DE: The canine and feline vertebrae. In: Textbook of Veterinary Diagnostic Radiology. Thrall (ed.). Louis: Saunders Elsevier, 2013, 172-93.

33 Young AN, du Plessis WM, Rodriguez D, Beierschmidt A: Thoracic radiographic anatomy in vervet monkeys (Chlorocebus sabaeus). J Med Primatol 2013; 42:310-7. 